\title{
Misfolding of Mutated Vasopressin Causes ER-Retention and Activation of ER-Stress Markers in Neuro-2a Cells
}

\author{
Zhongyu Yan, Andrea Hoffmann, Erin Kelly Kaiser, William C. Grunwald, Jr. and David R. Cool*
}

Department of Pharmacology \& Toxicology, Wright State University, Dayton, OH 45435

\begin{abstract}
Summary: Arginine-vasopressin (AVP) is a peptide hormone normally secreted from neuroendocrine cells via the regulated secretory pathway. In Familial Neurohypophyseal Diabetes Insipidus (FNDI), an autosomal dominant form of central diabetes insipidus, mutations of pro-vasopressin appear to accumulate in the endoplasmic reticulum (ER) causing a lack of biologically active AVP in the blood. To investigate the effect of pro-vasopressin mutations regarding intracellular functions of protein targeting and secretion, we created two FNDI-associated amino acid substitution mutants, e.g., G14R, and G17V in frame with green fluorescent protein (GFP) and pro-vasopressin (VP) in frame with red fluorescent protein (VP-RFP). Fluorescence microscopy of Neuro-2a cells expressing these constructs revealed co-localization of VP-GFP and VP-RFP to punctate granules along the length and accumulating at the tips of neurites, characteristic of regulated secretory granules. In contrast, the two FNDI-associated amino acid substitution mutants, e.g., G14R-GFP, and G17VGFP, were localized to a perinuclear region of the Neuro-2a cells characteristic of the endoplasmic reticulum. Coexpression of these mutants with VP-RFP showed VP-RFP was retained in the ER, co-localized with the mutants suggesting the formation of heterodimers as found in FNDI. Stimulated secretion experiments indicated that VP-GFP was secreted in an inducible manner whereas, G14R-GFP and G17V-GFP were retained to nearly $100 \%$ within the cells. Analysis by western blotting and semi-quantitative RT-PCR indicated an increased protein and mRNA expression for an ER resident molecular chaperone, BiP. Further analysis of ER-storage disease-associated proteins such as caspase 12 and CHOP showed an increase in these as well. The results suggest that G14R-GFP and G17V-GFP are retained in the ER of Neuro-2a cells, resulting in up-regulation of the molecular chaperone BiP, and activation of the ER-storage diseaseassociated caspase cascade system.
\end{abstract}

Keywords: Familial diabetes insipidus, GFP, regulated secretory pathway, sorting, vasopressin.

\section{INTRODUCTION}

The autosomal dominant form of central diabetes, Familial Neurohypophyseal Diabetes Insipidus (FNDI) is caused by mutations in one allele of the vasopressin gene, precursor to the peptide hormone, AVP [1-3]. FNDI mutations are correlated with the disruption of AVP processing, storage and secretion [1-3]. In normal individuals, synthesis of mature AVP requires glycosylation of its precursor pro-vasopressin (VP), packaging into secretory granules and proteolytic processing prior to secretion by the regulated secretory pathway [4, 5]. In contrast, FNDI mutations of vasopressin appear to accumulate in the endoplasmic reticulum (ER) causing a lack of biologically active AVP in the blood [6-9].

Symptoms of diabetes insipidus first appear in affected individuals between one and 6 years of age $[10,11]$. The effects of polydipsia and polyuria can vary, even among relatives with the same mutation $[12,13]$. However, one element common to several of the FNDI mutations is the accumulation of mutant vasopressin in the magnocellular neurons during early stages of the disease that

*Address correspondence to this author at the Wright State University, Boonshoft School of Medicine, Department of Pharmacology \& Toxicology, 240 Health Sciences Building, 3640 Colonel Glenn Hwy, Dayton, OH 45435, USA;

Tel: 937-775-2457; Fax: 937-775-7221;

E-mail: david.cool@wright.edu causes neurodegeneration of the magnocellular neurons over an extended period of time $[1,14,15]$. Evidence for this has been provided by autopsy studies and MRI data showing a reduction in the number of vasopressinergic neurons in the hypothalamus [15-17].

The autosomal dominance of FNDI and VP accumulation-associated degeneration of magnocellular neurons are also key elements found in other endoplasmic reticulum storage diseases (ERSD's) [18, 19]. Of significance are findings that in addition to cellular degeneration, the accumulation of proteins in the ER causes up-regulation of specific molecular chaperones called the unfolded protein response (UPR) [20, 21]. Several proteins are associated with the UPR, including the molecular chaperone, BiP (glucose regulated protein or Grp78) and PDI (protein disulfide isomerase) [22]. While the missorting of several vasopressin mutants has been described previously $[3,6,7,9,23-25]$, the cellular effect of mutant vasopressin has not yet been thoroughly investigated. Therefore, we became interested in investigating the effects that mutant vasopressin has on intracellular sorting and on cell death.

To characterize the subcellular localization and cellular effects of vasopressin and FNDI-associated mutants, we analyzed the intracellular fate of pro-vasopressin coupled to red fluorescence protein (VP-RFP) and two FNDI-associated mutant constructs with GFP wherein the glycine residue at 
position 14 or 17 was changed to anarginineor valine, respectively. The effect of these mutations on ER proteins and cell death were explored in a neuroblastoma cell line that has previously been used to study intracellular sorting of prohormones in our laboratory [26].

\section{MATERIALS AND METHODS}

\section{Vasopressin and Mutations}

Bovine preprovasopressin (VP) cDNA was kindly donated by Dr. Y. PengLoh (NIH) and amplified for subcloning as previously described [26]. The PCR product was digested with Nhe1/Pst1 and subcloned into the MCS of pEGFP-N1 (Clontech, Inc.). Mutations were created using the Stratagene Quick-Change Kit (Stratagene, Inc.). Using this technique, the FNDI-associated mutations were made; glycine at position 14 to an arginine (G14R-GFP) and glycine at position 17 to avaline (G17V-GFP). VP-RFP was made by digesting and ligating the VP cDNA into the Nhe 1 and BamH1 sites of the pdsRED-N1vector (VP-RFP). All constructs were sequenced to determine that the sequence was correct and in frame with GFP or RFP (Lark Technologies, Inc., Houston, TX).

\section{Cell Culture and Transfection}

Neuro-2a cells (ATCC CCL131, murine neuroblastoma) were routinely maintained in culture at $37^{\circ} \mathrm{C}, 10 \% \mathrm{CO}_{2}$, with DMEM containing 10\% FBS, $1 \mathrm{X}$ Pen/Strep/Fungizone (Gibco, Gaithersburg, MD). The cells were plated in 6 or 12 well plates 24 hours prior to transfection in complete DMEM lacking Fungizone. The cells were incubated with the plasmid constructs in a suspension of OptiMEM and Lipofectamine for 18 hours. For fluorescence microscopy, the cells were grown on $18 \mathrm{~mm}$ glass coverslips.

\section{AVP Secretion}

Basal AVP secretion was induced in transfected Neuro$2 \mathrm{a}$ cells with $500 \mu \mathrm{l} \mathrm{B1}$ medium containing $25 \mathrm{mM}$ Hepes, pH 7.4, 125mMNaCl, 5mMKCl, 25mM glucose and $0.25 \%$ BSA for $30 \mathrm{~min}$. After collecting basal AVP, stimulated AVP secretion was induced by $500 \mu 1$ B2 medium containing 25mM Hepes, $\mathrm{pH} 7.4,125 \mathrm{mMNaCl}, 5 \mathrm{mMKCl}$, $25 \mathrm{mM}$ glucose, $0.25 \% \mathrm{BSA}$ and $3 \mathrm{mM} \mathrm{BaCl}_{2}$ for $30 \mathrm{~min}$. Collected B1 and B2 medium were analyzed by affinity purification using Vector Fusion-Aid -GFP Kit followed by immunoblotting with anti-GFP antibodies.

\section{Affinity Purification by Vector Fusion-Aid -GFP Kit}

GFP-Affinity spin columns containing agarose coupled to $\alpha$-GFP antibody were equilibrated with PBS. Protein extracts or $\mathrm{B} 1$ and $\mathrm{B} 2$ secretion medium were added to the columns and incubated for $10 \mathrm{~min}$ with gentle agitation. Columns were centrifuged at $5000 \times \mathrm{g}$ for $1 \mathrm{~min}$ followed by collection of the flow through. After washing with PBS, 100 $\mu l$ of elution buffer was added (PBS, 2\% SDS). Columns were incubated for $5 \mathrm{~min}$ at $85^{\circ} \mathrm{C}$. Columns then were centrifuged at $5000 \times \mathrm{g}$ for $1 \mathrm{~min}$ and the eluates were collected for western-blotting analysis.

\section{BiP Retention Study}

Cells were lysed in $200 \mu \mathrm{l}$ lysis buffer $(0.5 \mathrm{M}$ Tris-Cl, EDTA $0.5 \mathrm{M}, \quad \mathrm{NP}-40 \quad 0.1 \%$, DTT $0.001 \mathrm{M}, \quad 1 \times$ protease inhibitor cocktail; $\mathrm{pH}$ 6.8) after 18 hours transfection and centrifuged at $13000 \times \mathrm{g}$. Total protein was determined by the Bio-Rad protein assay. Total protein, $100 \mu \mathrm{g}$, were affinity purified by Vector Fusion-Aid-GFP Kit (Vector Laboratories, Burlingame, CA). Affinity purified samples were separated on a $10 \%$ SDS-PAGE gel followed by immunoblotting with anti-BiP (1: 500) and anti-GFP $(1: 1000)$ specific antibodies.

\section{Immunocytochemistry and Fluorescence Microscopy}

Transfected cells grown on glass coverslips were fixed with $2 \%$ paraformaldehyde in $1 \mathrm{X}$ PBS containing $0.1 \%$ Triton X-100. The cells were blocked with $10 \%$ goat serum in $1 \mathrm{X}$ PBS for $1 \mathrm{hr}$, followed by incubation with primary antibodies specific for alpha-mannosidase II (1:2500) purchased from Dr. K. Moreman (University of Georgia, Athens, GA.) or BiP. After incubation, the cells were incubated with second goat anti-rabbit IgG conjugated to biotin followed by incubation with streptavidin conjugated to Texas Red (Roche, Indianapolis, IN). The labeled cells were post-stained with Hoechst 33258 dye for nuclear DNA (1 minute) followed by mounting with Gelmount (Biomeda, CA). GFP, RFP, Texas Red and Hoechst stained cells were visualized on a Leica DMR epifluorescent microscope and images captured using an Optronics DEI Magnafire CCD camera. The images were prepared using Adobe Photoshop and Illustrator CS3 software.

\section{Western Blots}

Cells to be analyzed by Western blot were grown in 6 well plates and transfected with the constructs. At the appropriate times, the media was removed and the cells were washed with PBS, scraped from the plates and centrifuged to a pellet. The PBS was removed and the cells were lysed in Tris-EDTA containing $5 \mathrm{mM}$ PMSF and aprotinin. The cell pellet was freeze-thawed 3 times followed by centrifugation at $15,000 \mathrm{Xg}$. The supernatant was separated from the cell debris. The sample $(30 \mu \mathrm{g})$ was combined with SDS-PAGE sample buffer (10\% SDS, bromophenol blue, $5 \mathrm{mM} \mathrm{b}$ mercaptoethanol and $20 \%$ glycerol) and boiled for $5 \mathrm{~min}$. The sample proteins were then separated on a $12 \%$ acrylamide gel and subsequently transferred to PVDF membrane for Western blotting by the ECF system (Amersham). The PVDF was blocked in 3\% non-fat dry milk, $0.3 \%$ Tween 20 in $1 \mathrm{X}$ PBS (blocking buffer) for one hour, followed by incubation with antibody to GFP (Clontech, Palo Alto, CA) for $1 \mathrm{hr}$. After washing for $5 \mathrm{~min}$ with $0.3 \%$ Tween 20 in $1 \mathrm{X}$ PBS, the membrane was incubated with a fluorescein tagged second antibody followed by another wash and finally incubation with an alkaline phosphatase conjugated third antibody to fluorescein. A substrate was added to the membrane and allowed to develop on the Fuji FLA2000 PhosphorFluorimager. Images were captured at 10 minute intervals for $1 \mathrm{hr}$. Quantitation was by ImageGauge v3.3 software (Fuji).

\section{REAL-TIME RT-PCR}

Total RNA for Real-Time PCR were isolated from the mouse neuroblastoma cell line, Neuro-2A, in TRIzol ${ }^{\circledR}$ via a chloroform/methanol extraction. Isolated RNA was dissolved in 1X TE and treated with DNase1 (DNA-free ${ }^{\mathrm{TM}}$, 
Ambion) for 20 minutes and DNase Turbo for 30 minutes. Approximately $50 \mathrm{ng}$ of total RNA was used for a multiplex. As an internal standard and for normalization, a primer set to GAPDH was used for all PCRs. PCR products were generated, optimized and analyzed by fluorescent Real-Time PCR on a BioRadi Cycler Real-Time PCR machine. The $\Delta \mathrm{Ct}$ for an individual sample,i.e., VP-GFP, was calculated by subtracting the GAPDH Ct value from the VP-GFP Ct value. This method of relative gene expression analysis has been described in detail by Livak and Schmittgen [27]. The individual sample $2^{-\Delta \Delta X T}$ values for each treatment group were averaged and compared to the VP-GFP controls to obtain the percent of control GFP mRNA. The formula for this is shown below. GOI stands for Gene of Interest.

$2^{-\Delta \Delta \mathrm{CT}}=2^{-(\mathrm{Ct}}{ }_{\text {GOI }}^{-\mathrm{Ct}}{ }_{\text {GAPDH }}{ }^{-(\mathrm{Ct}}{ }_{\text {GOIave }}{ }^{-\mathrm{Ct}}$ GAPDHave ${ }^{2}$

\section{RESULTS}

\section{Localization of VP-GFP in Neuro-2a Cells}

To directly examine the sorting of vasopressin, four chimeric vasopressin green or red fluorescence fusion protein constructs were made for expression in Neuro-2a cells and observation by fluorescence microscopy. The cDNA for pro-vasopressin or a mutant form of vasopressin was inserted into the multiple cloning site of the green fluorescence protein expression vector pEGFP-N1 (Fig. 1). Another chimeric construct was made by insertion of provasopressin in frame into the red fluorescence protein dsRED vector.

In Neuro-2a cells expressing VP-GFP, the chimeric protein was localized to punctate granules found along the neurites and in granules that appeared to accumulate at the tips of the neurites (Fig. 2A). Immunostaining for the ER resident protein, BiPwas found to be localized in a diffuse perinuclear area characteristic of the ER (Fig 2B). When the two images were merged, perinuclearVP-GFP did not appear to co-localize with $\mathrm{BiP}($ Fig. 2C). For comparison, Fig 2D shows VP-GFP co-localized with staining for $\alpha$-mannosidase
II (2E \&F), a protein associated with the Golgi.G14R-GFP and G17V-GFP fluorescence did not co-localize with $\alpha$ mannosidase II staining, suggesting that the mutant protein did not proceed to the Golgi (data not shown).In contrast, G14R-GFP fluorescence appeared to be similar to that of BiP (Fig. 2G). G14R-GFP fluorescence was observed to colocalizen early completely with BiP staining (Fig. 2H).Merge of the two micrographs shows nearly $100 \%$ overlap of the G14R-GFP and BiP staining in the ER (Fig. 2I). Likewise, G17V-GFP fluorescence appeared to be similar to that displayed by G14R-GFP and BiP (Fig. 2J). G17V-GFP fluorescence was also observed to colocalizenearly completely with BiP staining (Fig. 2K).Merge of the two micrographs shows nearly $100 \%$ overlap of the G17V-GFP and BiP staining in the ER (Fig. 2L). The results strongly suggest that the mutations altered the intracellular movement of mutant VP-GFP, i.e., the mutant proteins were retained in the ER.

\section{Mutant VP-GFP Causes Heterologous Disruption of VP- RFP Progression Through the ER and Golgi}

One of the hallmarks of FNDI is the apparent capability of mutant vasopressin to dimerize with normal vasopressin and prevent its egress from the ER to the Golgi and regulated secretory pathway (RSP). To study this process, we coexpressed VP-RFP with either normal VP-GFP or VP-GFP mutants. By using both GFP and RFP, we can simultaneously identify both mutant (green) and non-mutant (red) vasopressin in the cells.

As seen in Fig. (3A), VP-GFP fluorescence was observed in punctate granules as in Fig. (2A) and 2D. Likewise, VPRFP was sorted into punctate granules that extended along the neurites and accumulated at the tips (Fig. 3B). Cotransfection of the cells with VP-GFP indicated that VP-GFP and VP-RFP were co-localized in the same granules in these cells (Fig. 3C). However, when G14R-GFP (Fig. 3D) and G17V-GFP (Fig. 3G) were co-expressed with VP-RFP (Fig. $3 \mathbf{E} \& \mathbf{H}$, respectively), the pattern of fluorescence for $\mathrm{VP}$ -
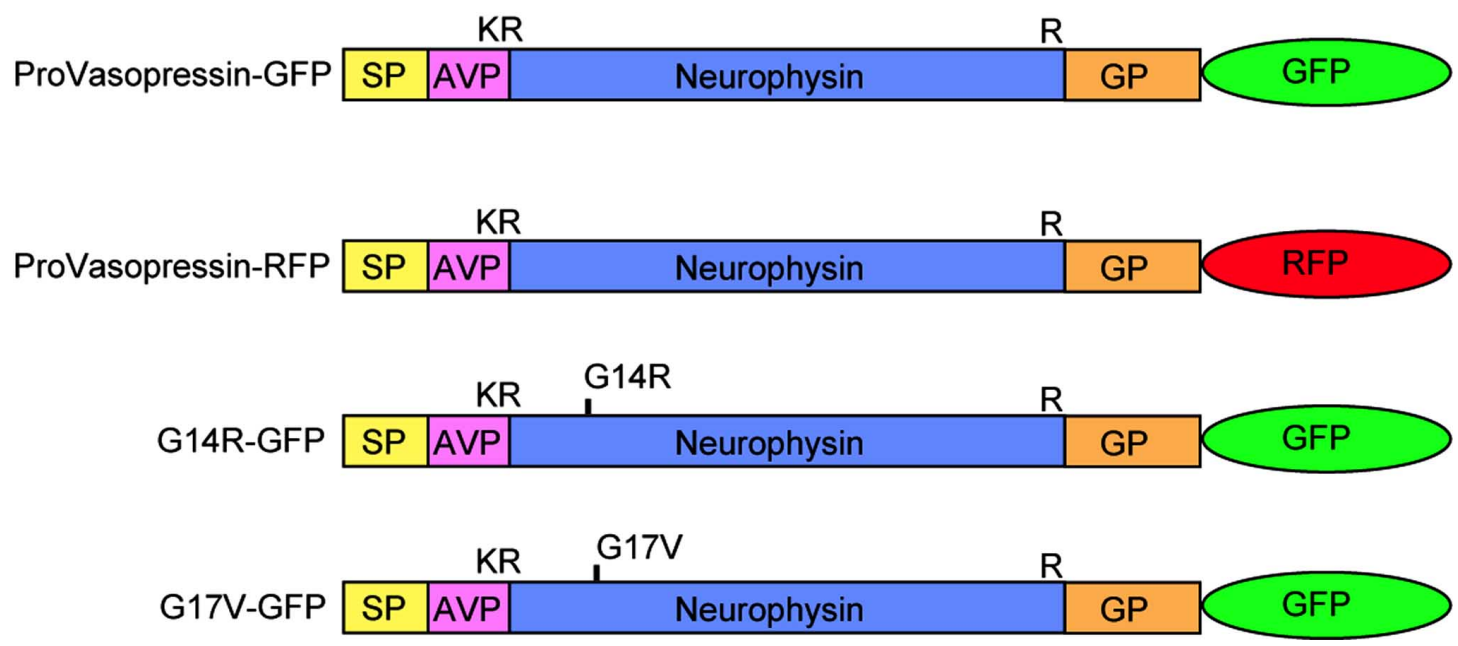

Fig. (1). Schematic diagram of GFP constructs. VP-GFP represents pre-provasopressin with GFP. VP-RFP is pre-provasopressin with dsRED. G14R-GFP and G17V-GFP are FNDI-associated mutants in which an arginine or valine residue has been substituted for a glycine at position 14 or 17 of neurophysin, respectively. $\mathrm{K}$ and $\mathrm{R}$ represent the single letter code for amino acids, lysine and arginine, respectively. SP: Signalpeptide;AVP: Arginine-vasopressin; NP: Neurophysin; GP: Glycoprotein. The single disulfide bond in AVP and 7 disulfide bridges in neurophysin are not shown. Glycopeptide does not contain cysteine residues but does contain one N-linked glycosylation site at amino acid residue 114. 

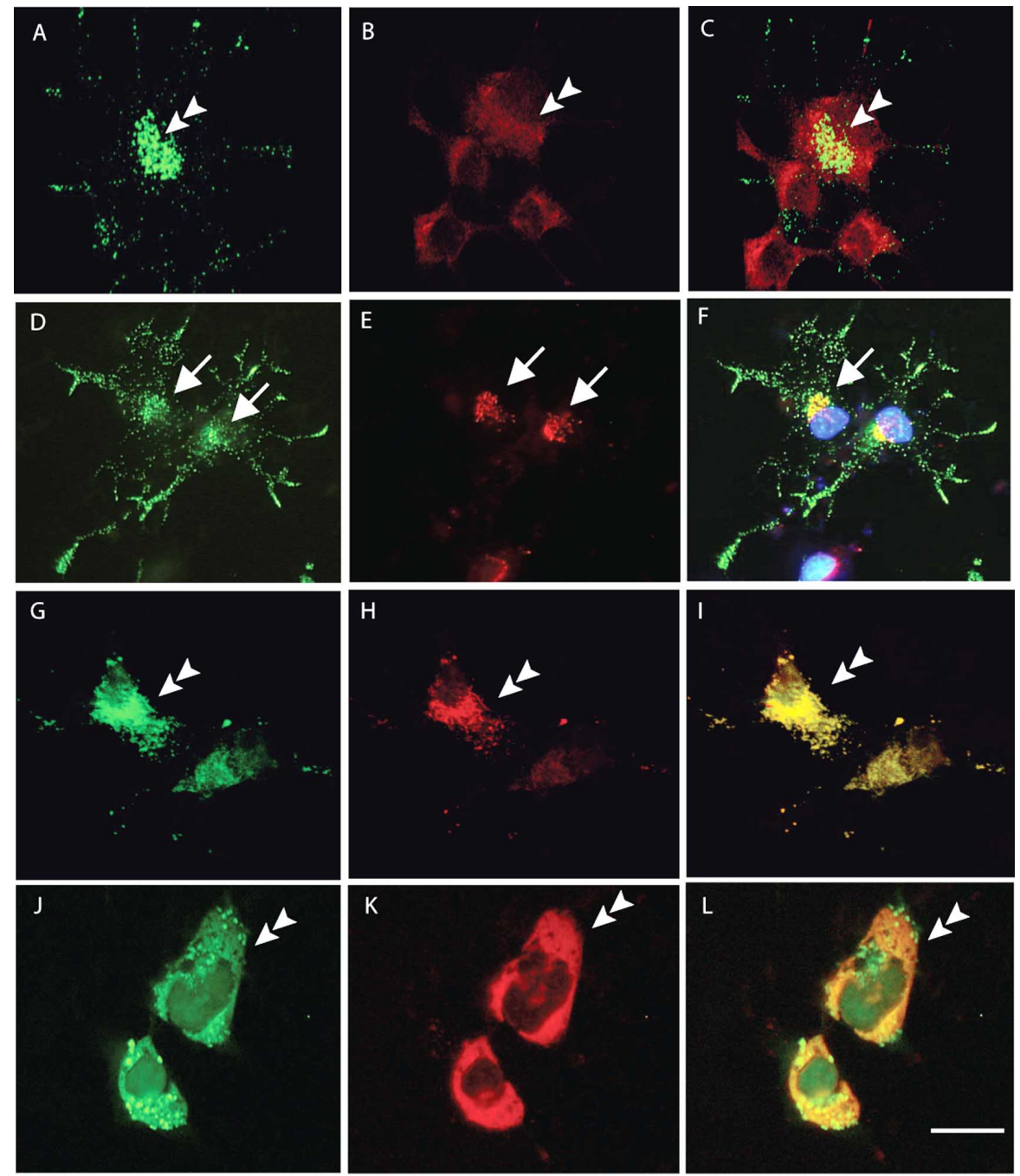

Fig. (2). Fluorescent micrographs of VP-GFP, G14R-GFP, and G17V-GFP constructs expressed in Neuro-2a cells. A) VP-GFP expression in Neuro-2a cells. Double-arrowheads indicate VP-GFP fluorescence in areas characteristic of the Golgi. B) BiP staining for ER. Doublearrowheads indicate Texas Red staining of BiP in the ER. C) Merge of A and B. Note that very little yellow is observed, indicating lack of overlap of VP-GFP and BiP. D) VP-GFP expression in Neuro-2a cells. Arrows indicate VP-GFP fluorescence in a perinuclear region characteristic of the Golgi. E) Alpha-Mannosidase II ( $\alpha$-MII) staining for the Golgi. Arrows indicate Texas Red staining of Golgi. F) Merge of D and E. Yellow indicates areas of co-localization of VP-GFP and ( $\alpha$-MII). The blue staining in (F) is Hoechst dye that binds to DNA to indicate the nucleus. G) G14R-GFP expression in Neuro-2a cells. Double-arrowheads indicate perinuclear accumulation of G14R-GFP. H) BiP staining for ER. Double-arrowheads indicate Texas Red staining of the ER. I) Merge of G and H. Yellow indicates areas of colocalization of VP-GFP and BiP. J) G17V-GFP expression in Neuro-2a cells. Double-arrowheads indicate perinuclear accumulation of G14R-GFP. K) BiP staining for ER. Double-arrowheads indicate Texas Red staining of the ER. L) Merge of J and K. Yellow indicates areas of co-localization of mutant VP-GFP and BiP. Bar= 10 micrometers

RFP was significantly altered. VP-RFP was no longer sorted to punctate granules, but rather, was found to be co-localized to the same perinuclear region as G14R-GFP and G17V-GFP (Fig. 3F \& I, respectively), i.e., a BiP-staining region indicative of the ER. The results support studies that demonstrated retention of normal vasopressin by accumulating with mutant vasopressin in the [6-8, 28].

\section{Stimulated Secretion of VP-GFP, G14R-GFP, and G17V- GFP}

The hallmark of the regulated secretory pathway is the release of peptide hormones in response to a stimulus [29]. The Neuro-2a cells are responsive to classic extracellular stimuli that cause depolarization resulting in stimulated secretion of peptide hormones. In the following experiments, Neuro-2a cells expressing VP-GFP, G14R-GFP and G17VGFP were stimulated with $3 \mathrm{mMBa}^{2+}$. The media and cell lysates were affinity purified by a Vector Fusion-Aid GFP kit and analyzed by western blotting with antibodies for GFP.

When Neuro-2a cells expressing VP-GFP were stimulated with $\mathrm{Ba}^{2+}$, VP-GFP was secreted in a regulated manner (Fig. 4). In comparison, in Neuro-2a cells expressing theG14R-GFP or G17V-GFP constructs, there was a significant $(p<0.05) 75-80 \%$ decrease in the amount of protein secreted in response to the same stimulation (Fig. 4). The results suggest that retention in the ER caused a reduction in the amount of mutant vasopressin secretion. 

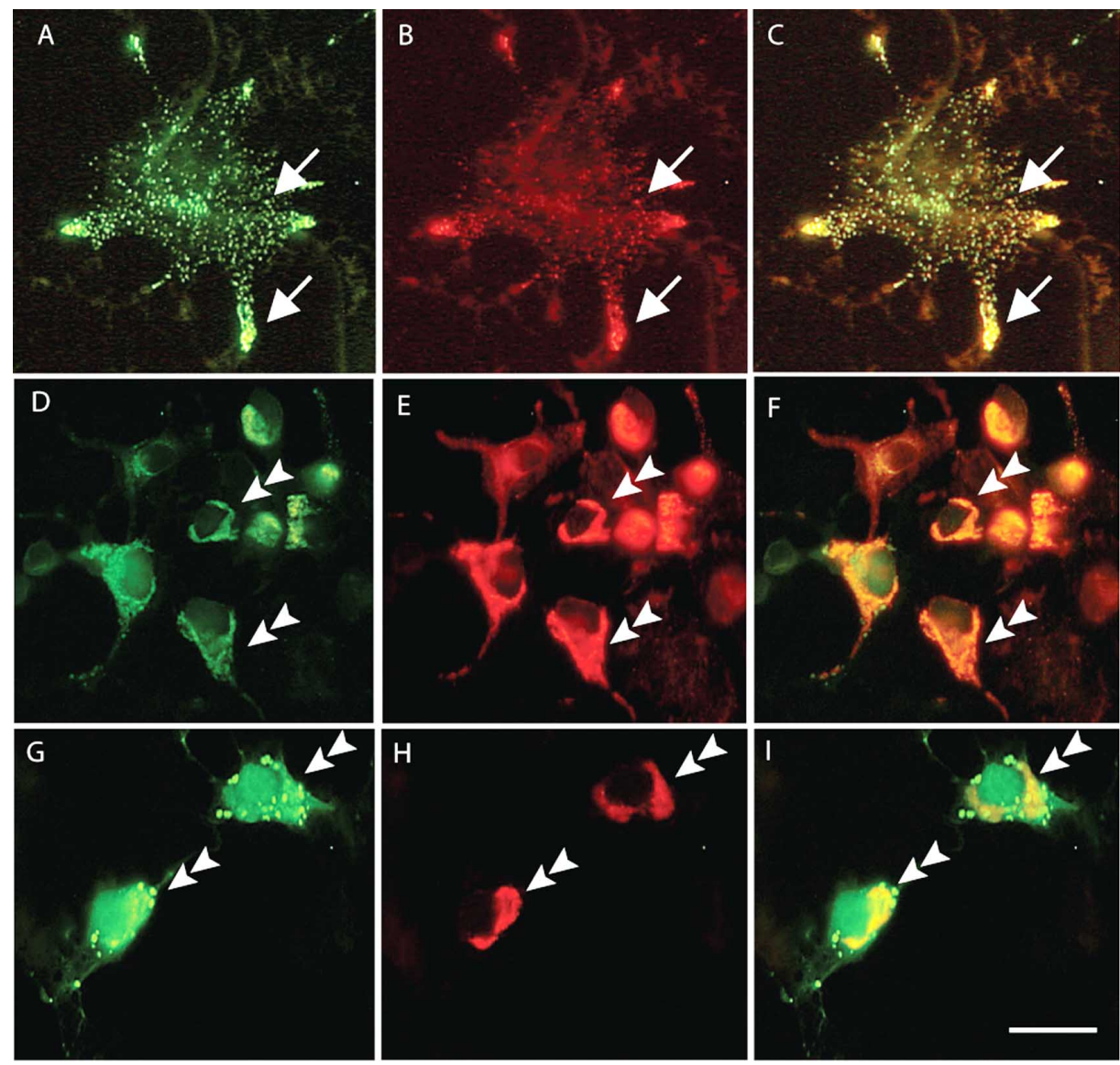

Fig. (3). Fluorescence micrographs of VP-GFP, mutant VP-GFP and VP-RFP constructs co-expressed in Neuro-2a cells. A) VP-GFP expression in Neuro-2a cells. Arrows indicate BP-GFP in secretory granules and the tips of neuritis.B) VP-RFP co-expression in the same cells. Double-arrowheads indicate VP-RFP in secretory granules and at the tips of neuritis. C) Merge of A and B. Yellow indicates areas of co-localization of VP-GFP and VP-RFP. D) G14R-GFP co-expression with VP-RFP (E) in Neuro-2a cells. F) Merge of the two micrographs indicating yellow where overlap occurs. G) G17V-GFP co-expression with VP-RFP (H) in Neuro-2a cells. (I) Merge of the two micrographs indicating where overlap occurs. Arrows indicate punctate granules in the neurites of the green or red fluorescence. Bar= 10 micrometers

\section{Effect of G14R-GFP and G17V-GFP on ER Chaperone Protein BiP}

The evidence presented in this paper and from others suggests that G14R-GFP and G17V-GFP are retained in the ER, most probably as a result of the mutation that caused a perturbation in the folding of mutant vasopressin [30]. We wanted to determine whether retention in the ER had an effect on the ER chaperones involved in protein folding and the unfolded protein response. The ER chaperone BiP (GRP78) was chosen since its expression has been shown to be up-regulated in response to protein misfolding $[19,31$ 34]. Neuro-2a cells were transfected with VP-GFP, G14RGFP or G17V-GFP constructs, and allowed to incubate for 24 hours. The cells were then lysed and GFP was affinity purified from the lysates. We analyzed the affinity-purified proteins by western blotting and analyzed each of the constructs using antibodies for BiP (Fig. 5A). The western blot results indicate that BiP protein levels were significantly $(\mathrm{p}<0.05)$ increased in both G14R-GFP and G17V-GFP expressing cells compared to VP-GFP cells (Fig. 5B). In contrast, protein disulfide isomerase erase and $\alpha$ mannosidase II protein levels were not significantly altered in the G14R-GFP or G17V-GFP groups compared to VPGFP cells (data not shown).
To correlate the $\mathrm{BiP}$ protein increases with mRNA expression, total RNA was isolated after $24 \mathrm{hrs}$ and analyzed by semi-quantitative RT-PCR using primers for BiP that produced a 120 bp PCR product. In the same reaction tube, another set of primers was used that yielded a $105 \mathrm{bp} \mathrm{PCR}$ product for the housekeeping gene, GAPDH mRNA. RealTimeRT-PCR was performed on VP-GFP, G14R-GFP and G17V-GFP transfected cells. The PCR results indicated that the BiP mRNA levels were significantly $(\mathrm{p}<0.05)$ increased2.5 and 2.3 fold in the G14R-GFP and G17V-GFP cells, respectively (Fig. 5C) in comparison to VP-GFP transfected cells. To study this further, we examined the effect that the mutation had on $\alpha$-mannosidase II, a Golgilocalized protein and protein disulfide isomerase (PDI). Accordingly, mRNA levels were found to be the same in G14R-GFP and G17V-GFP compared with VP-GFP expressing cells (data not shown).

\section{Effect of G14R-GFP and G17V-GFP on Markers of Cell Death}

The ultimate fate of vasopressinergic cells expressing FNDI-mutations in humans is cell death and loss of the neurons. To examine the effect of the two mutations on transfected cells, we analyzed caspase 12, a cell-death caspase,known to be activated in mouse cells in response to 


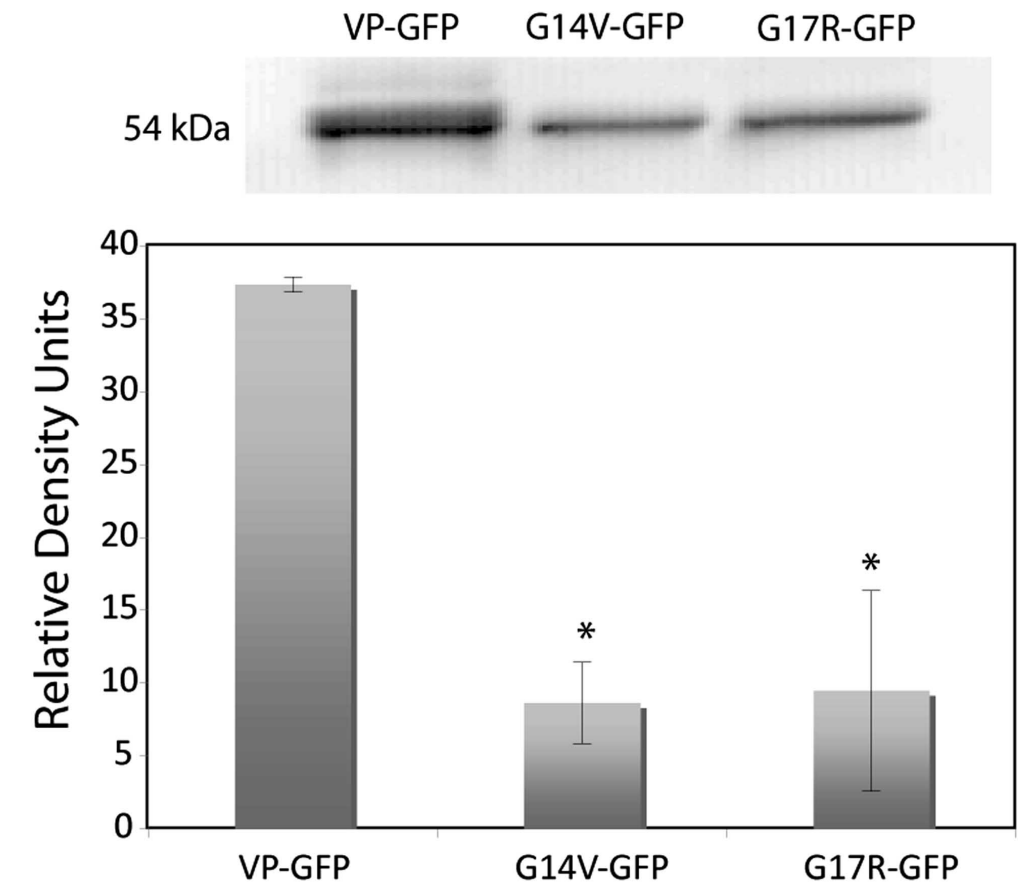

Fig. (4). Secretion of GFP from Neuro-2a cells. Secretion media from Neuro-2a cells transfected with the constructs was extracted using a GFP-specific affinity column. The GFP proteins extracted from the secretion media were run on a denaturing SDS-PAGE and quantitated by western blotting with antibodies to GFP. Due to the nature of the extraction process, GFP was normalized to the amount of protein loaded on the gel, $30 \mu \mathrm{g}$. The data represents the mean \pm SEM from 4 independent experiments. Asterisks indicate both G14R-GFP and G17V-GFP showed significant difference $(\mathrm{p}<0.05)$ from VP-GFP.

ER damage or stress [35-38]. Protein was extracted from cells expressing the VP-GFP, G14R-GFP and G17V-GFP constructs and analyzed by western blotting (Fig. 6A). The results clearly show a significant increase $(\mathrm{p}<0.05)$ in activated caspase $12(35 \mathrm{kDa})$ in the extracts from cells carrying either of the two mutations in contrast to cells expressing VP-GFP (Fig. 6B). A smaller form of caspase 12, i.e., $17 \mathrm{kDa}$, was also observed to increase in these cells (Fig. 6B). The $35 \mathrm{kDa}$ form of caspase 12 corresponds to the larger epitope-containing region formed from cleavage at T132/A133 and the $17 \mathrm{kDa}$ form is the smaller C-terminal region formed by cleavage at K158/T159 [39, 40]. At the time points tested, caspases 3 and 9 were unaffected by the mutants (data not shown).

Another protein associated with the ER-storage disease pathway and unfolded protein response (UPR) is CHOP (C/EBP Homology Protein) also known as GADD153 (Growth Arrest DNA Damage 153) [41, 42]. CHOP is a nuclear protein that is induced by ER stress and acts to inhibit DNA binding to promoter C/EBP sites by dimerizing with C/EBP [43-47]. The CHOP/C/EBP complex then forms heterodimers with other promoter regions to activate other genes, e.g., Jun/Fos and ultimately induces apoptosis [41]. We analyzed CHOP expression by Real Time-RT PCR for changes in the mRNA levels following expression of VPGFP, G14R-GFP, and G17V-GFP. There was a significant 5-10-fold increase in the CHOP mRNA in the same cells (Fig. 7). Western blots suggested an increase in the CHOP protein in cells expressing G14R-GFP and G17V-GFP compared with controls (data not shown). The results clearly establish a pattern of activation of the ER-stress pathway that would eventually lead to cell death by apoptosis.

\section{DISCUSSION}

The autosomal dominant disease, familial neurohypophyseal diabetes insipidus is characterized by an insufficient amount of AVP being released into the blood [9, 25, 48-50]. The reason for the lack of AVP secretion appears to be the presence of a variety of mutations in the provasopressin gene that compromise the folding of provasopressin causing its aggregation and retention in the ER that leads to a malfunction in sorting and processing $[25,30$, 48-54]. Correspondingly, the objectives of our study were to investigate how mutations in the neurophysin region of vasopressin could have adverse effects on; 1) folding and dimerization of the prohormone; 2) intracellular trafficking and secretion from the cell; and 3) the fate of the cell itself.

Previous work has shown that pro-vasopressin's ability to be sorted into the regulated secretory pathway is directly related to its 3-dimensional folding which is considered to be critical for dimerization of then europhysin region of the provasopressin molecules [6-8, 25, 30, 55-57]. In one of these studies, folding of the same G17V mutation that we used, was analyzed by nuclear magnetic resonance (NMR) and circular dichroism (CD) spectroscopy and was found to have a much lower folding efficiency than wild-type vasopressin or even $\Delta \mathrm{E} 47$ and $\mathrm{A} 29 \mathrm{G}$ mutations [30]. This is proposed to be due to the interruption of the beta-turn in neurophysin in this area [49]. In studies on other mutations the ability of to dimerize was found to not be adversely affected by the G57S/R or $\Delta \mathrm{E} 47$ mutations, but was affected by the $87-$ Stop mutation. To test for intermolecular interactions, we used two mutations that mark the beginning and end of the betaturn between two beta-pleated sheets in the neurophysin 

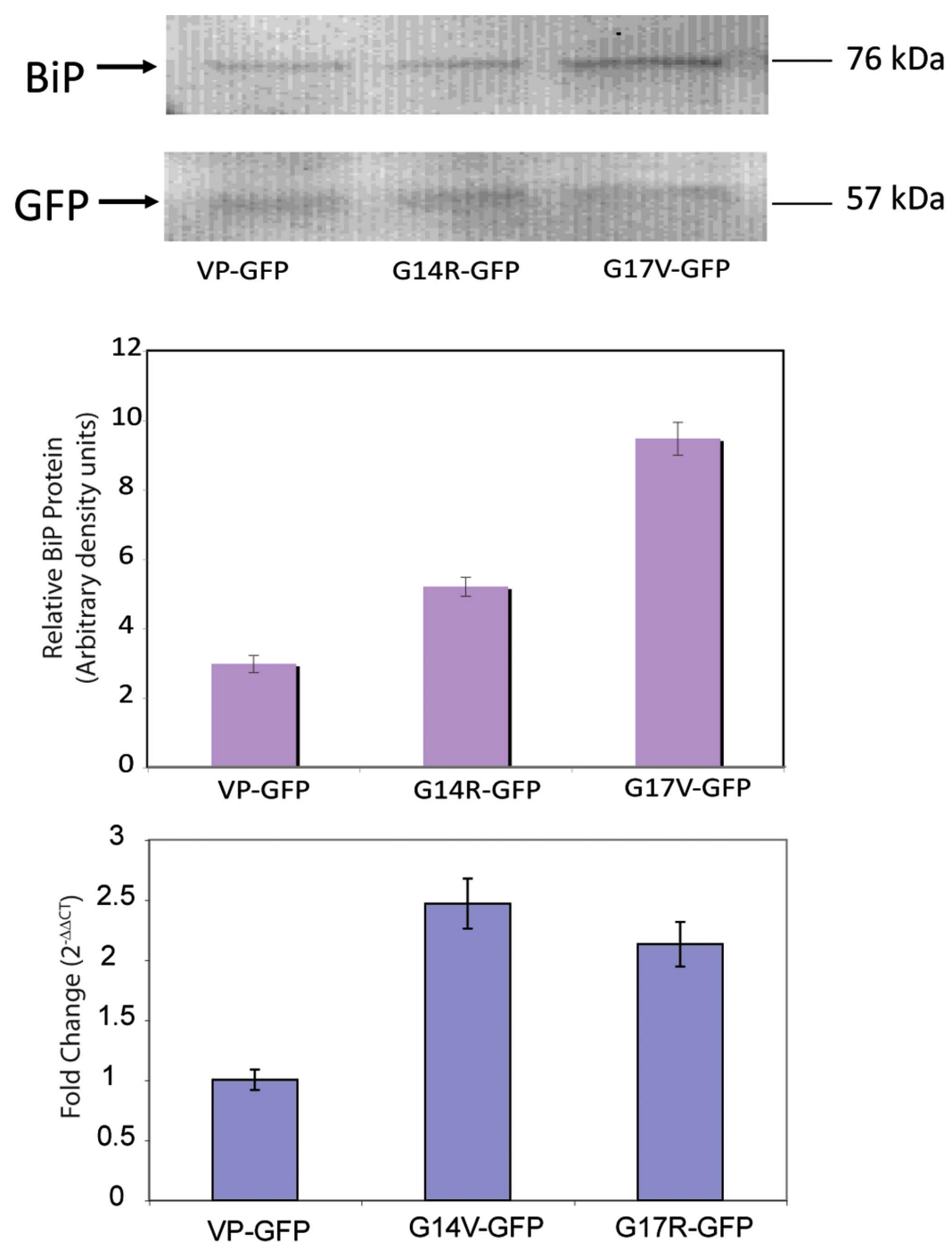

Fig. (5). Western blot and Semiquantitative Real Time RT-PCR for BiP. A) GFP protein was extracted from cells expressing the VP-GFP or mutant VP-GFP constructs using a GFP affinity column. BiP co-eluting with GFP indicative of VP-GFP or mutant VP-GFP was analyzed by western blots. The density of each BiP-specific band was normalized to GFP from the same lane. B) Total RNA was extracted from Neuro2a cells transfected with the chimeric constructs. B) Semi-quantitative RT-PCR was conducted for each of the constructs and normalized against an internal RT-PCR standard, GAPDH. The RTPCR results were normalized to VP-GFP and analyzed by the method of Livak [2001]. The data for both western blots and semiquantitative RT-RTPCR are expressed as the mean \pm SEM from three independent experiments. Asterisks indicate G14R-GFP and G17V-GFP showed a significant difference ( $\mathrm{p}<0.05)$ from VP-GFP.

molecule, e.g.,G14R-GFP and G17V-GFP, respectivelyand co-transfected them with VP-RFP into Neuro-2a cells.

In cells expressing the G14R-GFP and G17V-GFP mutants, the GFP fluorescence was mostly retained in the ER, similar to observations by other investigators using a variety of FNDI-associated mutants. Punctate granules were not seen in these cells suggesting that the mutant VP-GFP was significantly blocked from entry into the RSP [7, 24, 26, $56,58]$. We then developed a model of FNDI in which the cDNA for wild-type pro-vasopressin is coupled to the cDNA for red fluorescent protein (VP-RFP) that can be coexpressed with the mutant VP-GFPs.The majority of cells co-expressing mutant vasopressin with normal vasopressin displayed both red and green fluorescence co-localized in the ER. This is the first direct visual evidence that heterodimers can form between mutant VP-GFP and normal VP-RFP. If dimerization did not occur in the ER, then VP-RFP should have continued to traffic through to the Golgiand RSP. The results from our experiments substantiate the autosomal dominant effect of the FNDI mutations to dimerize and prevent the movement of normal pro-vasopressin from the ER to the Golgi and regulated secretory pathway.

Aggregation in the ER has been proposed to be due to the formation of fibrillar aggregates by intermolecular disulfide bond formation [59]. While our study was not designed to directly test this hypothesis, we have no evidence that this is not a mechanism that could explain our results. However, the fact that heterodimers were able to form in our experiments suggests that disulfide bridge formation may not have been perturbed as much in our two mutants as those in Birk's study. Likewise, in a previous NMR study on G17V-GFP, the disulfide bond formation was found to be normal and not perturbed by the misfolding caused by the mutation [30]. Differences in cell lines (COS-1 in Birk versus Neuro-2a in 
A

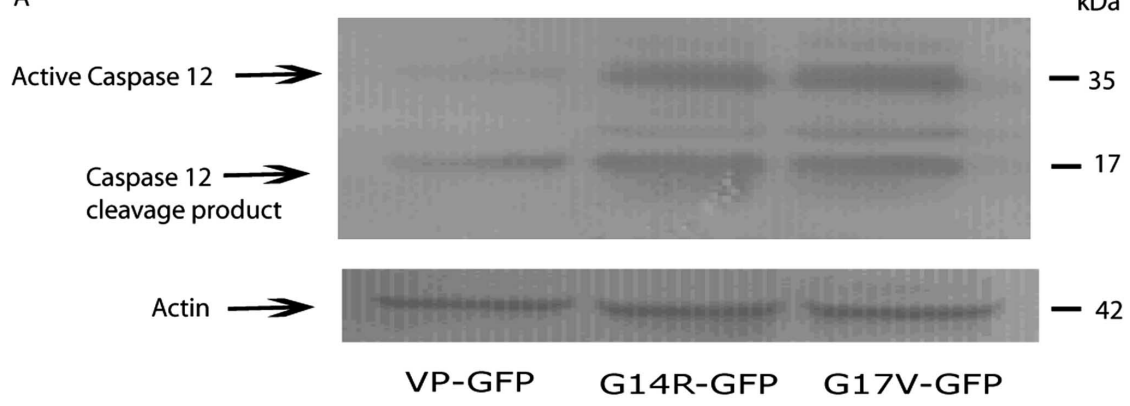

B
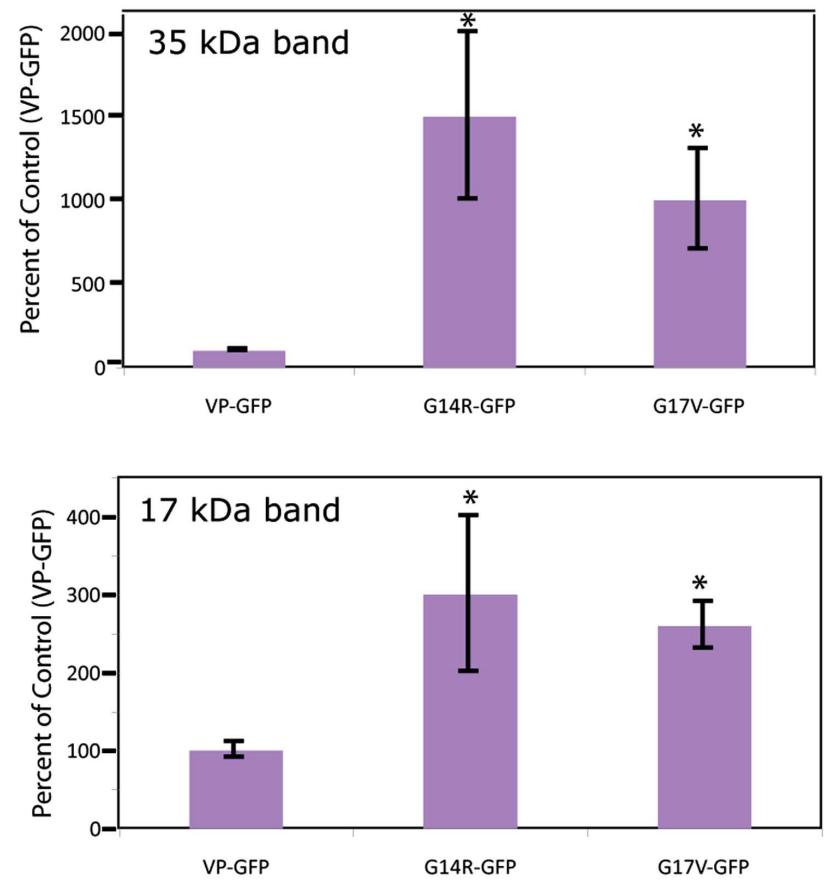

Fig. (6). Activated Caspase 12 is increased in cells expressing G14R-GFP and G17V-GFP. A) Representative western blot showing activated caspase $12(25 \mathrm{kDa})$ in the nuclei of cells expressing VP-GFP and the mutant VP-GFP constructs. B) Graph showing the relative levels of activated caspase 12 (35 and $25 \mathrm{kDa}$ ) in the cytoplasm of cells expressing the mutants or VP-GFP. Density of the caspase 12 bands was normalized to actin staining in each lane. The results represent the mean \pm SEM from 3 independent experiments. Asterisks indicate G14RGFP and G17V-GFP showed a significant difference $(\mathrm{p}<0.05)$ from VP-GFP.

our study), length of time for the experiments (48-72 hours for Birk versus 18-24 hours for our study) and the types of mutations could be an explanation for these findings. These types of aggregates were also not found in an in vivo model of FNDI (C67X in which a stop codon has been inserted at cysteine 67 of neurophysin) suggesting that cell type, time or type of mutation may play a role in aggregate formation [35].

Stimulated secretion of a peptide hormone from neuroendocrine cells is considered to be one of the most important points of regulation of the hormone's function. The predicted outcome of our immunocytochemical studies would be decreased secretion of the mutated vasopression molecule. In the case of FNDI, secretion of the peptide hormone AVP is attenuated by misfolding of the vasopressin molecule and retention in the ER. In the present study, only a small amount of the mutant vasopressin molecules exited the ER, through the Golgi to either the regulated or constitutive secretory pathway. In vivo studies also indicate a small amount of mutant vasopressin was secreted into the circulation in some patients [9, 25, 48-50]. Thus, the folding of the neurophysin region can be viewed as a predictor of the ability of pro-vasopressin to 1) exit the ER; 2) sort to the regulated secretory pathway; and 3 ) be secreted from the cell.

In another ER storage disease, thyroglobulin is improperly folded causing retention in the ER and induction of specific molecular chaperones [60]. For our study, we investigated the expression of a specific chaperone in response to expression of mutant vasopressin, i.e., BiP. BiP is a protein involved in binding to newly-synthesized proteins [20, 33, 45, 61]. Most importantly, since it is a member of the HSP70 family of molecular chaperones, BiP also binds to misfolded or unassembled proteins that cannot exit the ER [20]. Due to BiP's role in retaining misfolded proteins in the ER, our hypothesis was that as more misfolded proteins are made, more BiP is necessary for ER retention. The results from our experiments in which $\mathrm{BiP}$ 


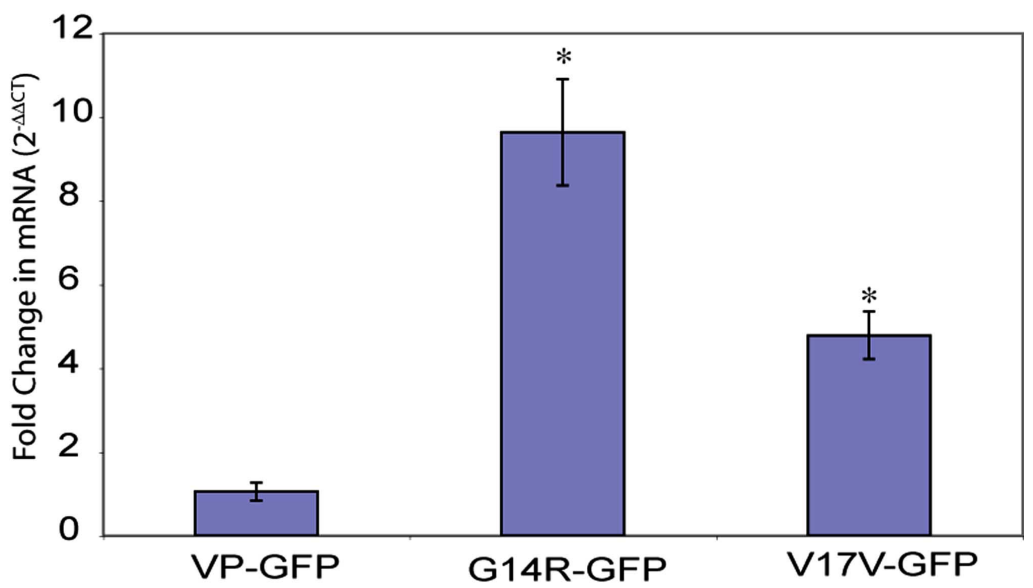

Fig. (7). mRNA is increased in cells expressing G14R-GFP and G17V-GFP. Semiquantitative Real Time RT-PCR showing increased mRNA for CHOP in cells expressing G14R-GFP and G17V-GFP compared to VP-GFP. The CT values for the CHOP data were normalized to GAPDH and are expressed as fold change as determined by the method of Livak [2001]. The data represent the mean \pm SEM from 3 independent experiments. Asterisks indicate G14R-GFP and G17V-GFP showed significant difference $(p<0.05)$ from VP-GFP.

protein and mRNA G14R-GFP and G17V-GFP expressing cellswere both induced from 1.5-3 fold higher than in cells expressing VP-GFP, support this hypothesis. The binding and retention cycle causes a drop in free $\mathrm{BiP}$ that would signal the need for the cell to make more BiP. The increase we saw, however, was small compared to the thyroglobulin system $[33,60,62]$. One explanation is that the degradative machinery of the ER may have been able to keep pace with the amount of misfolded protein being made over the short time of our experiments (18-24 hours). We also measured the protein and mRNA levels for protein disulfide isomerase and the Golgi protein, alpha-mannosidase II. There was no significant difference in the mRNA or protein levels of PDI in the cells expressing the mutants, most probably because disulfide folding was not impaired by either of the mutations. Thus, there was no need to increase its production. Further support for this was the finding that formation of the disulfide bonds was not found to be impaired in a previous study using the G17V mutation [30]. In interesting contrast to PDI, there was a large increase in alpha-mannosidase II mRNA in the VP-GFP expressing cells and a significant decrease in cells expressing the mutations (data not shown). These results are consistent with the increased traffic of VPGFP through the Golgi but lack of mutant vasopressin movement out of the ER to the Golgi.

One of the observations from MRIs of patients with FNDI is the disappearance of the 'white spot' representative of the magnocellular vasopressinergic neurons [10, 12, 50, 54]. This is thought to occur over time as the misfolded vasopressin is retained in the ER, eventually becoming toxic to the ER and cell. In a mouse model of FNDI, there was a reported decrease in the number of vasopressinergic neurons of the paraventricular nucleus and supraopticnucleus over 18 months [35]. In our study, we found that the activated form of caspase 12 was increased in cells expressing G14R-GFP and G17V-GFP compared with the VP-GFP control. Caspase 12 in mouse cells is considered an initiator of the ER stress pathway for cell death [36, 38, 63]. The results presented here clearly establish that this pathway is activated, potentially leading to apoptosis. Further analysis of the $\mathrm{CHOP}$ protein associated with stress-induced apoptosis also establishes that it is induced in cells expressing both of the mutants and that its mRNA is also increased. This reinforces the proposal that apoptosis is the primary cause of cell death in FNDI and not necrosis. In the C67X mouse model of FNDI, TUNEL assays and immunocytochemistry failed to show apoptotic markers, e.g., caspase 3, or CHOP [35]. The different results could be related to the type of mutation, its severity in altering intracellular trafficking through the secretory pathway or cell-specific differences.

The results presented here suggest that mutations associated with the autosomal dominant form of central diabetes insipidus do result in a dominant phenotype when normal vasopressin is co-expressed in the same cells. The result is the retention of both normal and mutated provasopressin in the ER that correlates with an increase in the ER chaperone $\mathrm{BiP}$, a marker for the unfolded protein response [64, 65]. Markers for ER-stress associated apoptosis, i.e., caspase 12 and $\mathrm{CHOP}$ as induced by the expression of the two pro-vasopressin mutants suggest that apoptosis may play a role in the disappearance of vasopressinergic neurons observed in familial neurohypophyseal diabetes insipidus [1, 66, 67].

\section{ACKNOWLEDGEMENTS}

We thank the Proteome Analysis Laboratory in the Dept of Pharmacology \&Toxicology at WSU for use of the facility for this project. This research was supported by a grant from the NIH (R01-DK58111-05).

\section{CONFLICT OF INTREST}

None declared.

\section{REFERENCES}

[1] Braverman L, Mancini J, McGoldrick D. Hereditary diabetes insipidus: a case report with autopsy findings. Ann Intern Med $1965 ; 63: 503-8$.

[2] Forssman H. On hereditary diabetes insipidus with special regard toa sex-linked form. Acta Medica Scandinavica Supplement 1945.

[3] Levinger EL, Escamilla RF. Hereditary diabetes insipidus: report of 20 cases in 7 generations. J Clin Endocrinol 1955; 15: 547-52.

[4] Brownstein MJ. Biosynthesis of vasopressin and oxytocin. Annu Rev Physiol 1983;45:129-35.

[5] Brownstein MJ, Russell JT, Gainer H. Synthesis, transport, and release of posterior pituitary hormones. Science 1980; 207(25) : 373-8. 
[6] Ito M, Jameson JL, Ito M. Molecular basis of autosomal dominant neurohypophyseal diabetes insipidus. J Clin Invest 1997; 99(8) : 1897-905.

[7] Ito M, Yu RN, Jameson JL, Ito M. Mutant vasopressin precursors that cause autosomal dominant neurohypophyseal diabetes insipidus retain dimerization and impair the secretion of wild-type proteins. J Biol Chem 1999; 274(13): 9029-37.

[8] Nijenhuis M, Zalm R, Burbach J. Mutations in the vasopressin prohormone involved in diabetes insipidus impair endoplasmic reticulum export but not sorting. J Biol Chem 1999; 274: 21200-8.

[9] Siggaard C, Rittig S, Corydon TJ, et al. Clinical and molcular evidence of abnormal processing and trafficking of the vasopressin preprohormone in a large kindred with familial neurohypophyseal diabetes insipidus due to a signal peptide mutation. J Clin Endocrinol Metab 1999; 84: 2933-41.

[10] Baylis PH, Robertson GL. Vasopressin function in familial cranial diabetes insipidus. Postgrad Med J 1981; 57: 36-40.

[11] Kaplowitz PB, D'Ercole AJ, Roberston GL. Radioimmunoassay of vasopressin in familial cetnral diabetes insipidus. J Pediatr 1982; 100: 76-81.

[12] Repaske DR, Medlej R, Gultekin EK, et al. Heterogeneity in clinical manifestation of autosomal dominant neurohypophyseal diabetes insipidus caused by a mutation encoding Ala-1-Val in the signal peptide of the arginine vasopressin/neurophysinII copeptin precursor. J Clin Endocrinol Metab 1997; 82: 51-6.

[13] Repaske DR, Summar ML, Krishnamani MRS, et al. Recurrent mutations in the vasopressin-neurophysin II gene cause autosomal dominant neurohypophyseal diabetes insipidus. J Clin Endocrinol Metab 1996; 81: 2328-34.

[14] Green J, Buchan G, Alvord JE, Swanson A. Hereditary and idiopathic types of diabetes insipidus. Brain 1967; 90 : 707-14.

[15] Rutishauser J, Boni-Schnetzler M, Boni J, et al. A novel point mutation in the translation initiation codon of the pre-provasopressin-neurophysin II gene: cosegregation with morphological abnormalities and clinical symptoms in autosomal dominant neurohypophyseal diabetes insipidus. J Clin Endocrinol Metab 1996; 81(1): 192-8.

[16] Moses AM. Use of T1-weighted MR imaging to differentiate between primary polydipsia and central diabetes insipidus. Am J Neuroradiol 1992; 13: 1273-7.

[17] Sato N, Ishizaka H, Yagi H, Matsumoto M, Endo K. Posterior lobe of the pituitary in diabetes insipidus: dynamic MR imaging. Radiology 1993; 186: 357-60.

[18] Callea F, Brisgotti M, Fabbretti G, Bonino F, Desment VJ. Hepatic endoplasmic reticulum storage diseases. Liver 1992; 114: 357-62.

[19] Kim PS, Arvan P. Endocrinopathies in the family of endoplasmic reticulum (ER) storage diseases: disorders of protein trafficking and the role of ER molecular chaperones. Endocr Rev 1998; 19(2) : 173-202.

[20] Gething MJ. Role and regulation of the ER chaperone BiP. Cell Dev Biol 1999; 10: 465-72.

[21] Mori K, Kawahara T, Yoshida H, Yanagi H, Yura T. Signaling from the ER to the nucleus: transcription factor with a basic-leucine zipper motif is required for the unfolded protein-repsonse pathway. Genes Cells 1996; 1: 803-17.

[22] Kozutsumi Y, Segal M, Normington K, Gething MJ, Sambrook J. The presence of malfolded proteins in the endoplasmic reticulum signals the induction of glucose regulated proteins. Nature 1988; 332: 462-4.

[23] Ito M, Oiso Y, Murase T, et al. Possible involvement of inefficient cleavage of preprovasopressin by signal peptidase as a cause for familial central diabetes insipidus. J Clin Invest 1993; 91(6): 256571.

[24] Nijenhuis M, Zalm R, Burbach JPH. Mutation in the vasopressin prohormone involved in diabetes insipidus impair endoplasmic reticulum export but not sorting. J Biol Chem 1999; 274(30): 21200-8.

[25] Rittig S, Robertson GL, Siggaard C, et al. Identification of 13 new mutations in the vasopressin-neurophysin II gene in 17 kindreds with familial autosomal dominant neurohypophyseal diabetes insipidus. Am J Hum Genet 1996; 58: 107-17.

[26] Cool DR, Jackson SB, Waddell KS. Structural requirements for sorting pro-vasopressin to the regulated secretory pathway in a neuronal cell line. Open Neuroendocrinol J 2008; 1: 1-8.
[27] Livak KJ, Schmittgen TD. Analysis of relative gene expression data using real-time quantitative PCR and the 2(-Delta Delta C(T)) Method. Methods 2001; 25(4): 402-8.

[28] Si-Hoe SL, De Bree FM, Nijenhuis M, et al. Endoplasmic reticulum derangement in hypothalamic neurons of rats expressing a familial neurohypophyseal diabetes insipidus mutant vasopressin transgene. J FASEB 2000; 14(12) : 1680-4.

[29] Kelly RB. Pathways of protein secretion in eukaryotes. Science 1985; 230(4721): 25-32.

[30] Eubanks S, Nguyen TL, Deeb R, et al. Effects of diabetes insipidus mutations on neurophysin folding and function. J Biol Chem 2001; 276(32): 29671-80.

[31] Kim PS, Kwon OY, Arvan P. An endoplasmic reticulum storage disease causing coongenital goiter with hypothyroidism. J Cell Biol 1996; 133: 517-27.

[32] Bonifacino JS, Lippincott-Schwartz J. Dedradation of proteins within the endoplasmic reticulum. Curr Opin Cell Biol 1991; 3: 592-600.

[33] Kim PS, Arvan P. Calnexin and BiP act as sequential molecular chaperones during thyroglobulin folding in the endoplasmic reticulum. J Cell Biol 1995; 128: 29-38.

[34] Kohno K, Normington K, Sambrook J, Gething MJ, Mori K. The promoter region of the yeast KAR2 (BiP) gen contains a regulatory domain that responds to the presence of unfolded proteins in the endoplasmic reticulum. Mol Cell Biol 1993; 13: 877-90.

[35] Russell TA, Ito M, Yu RN, et al. A murine model of autosomal dominant neurohypophyseal diabetes insipidus reveals progressive loss of vasopressin-producing neurons. J Clin Invest 2003; 112(11): 1697-706.

[36] Nakagawa T, Zhu H, Morishima N, et al. Caspase-12 mediates endoplasmic-reticulum-specific apoptosis and cytotoxicity by amyloid-beta. Nature 2000; 403(6765): 98-103.

[37] Rao RV, Hermel E, Castro-Obregon S, et al. Coupling endoplasmic reticulum stress to the cell death program: Mechanism of caspase activation. J Biol Chem 2001; 276(36): 33869-74.

[38] Rao RV, Peel A, Logvinova A, et al. Coupling endoplasmic reticulum stress to the cell death program: role of the ER chaperone GRP78. FEBS Lett 2002; 514(2-3): 122-8.

[39] Nakagawa T, Yuan J. Cross-talk between two cysteine protease families. Activation of caspase-12 by calpain in apoptosis. J Cell Biol 2000; 150(4): 887-94.

[40] Shiraishi H, Okamoto H, Yoshimura A, Yoshida H. ER stressinduced apoptosis and caspase-12 activation occurs downstream of mitochondrial apoptosis involving Apaf-1. J Cell Sci 2006; 119: 3958-66.

[41] Matsumoto M, Minami M, Takeda K, Sakao Y, Akira S. Ectopic expression of CHOP (GADD153) induces apoptosis in M1 myeloblastic leukemia cells. FEBS Lett 1996; 395(2-3): 143-7.

[42] McCullough KD, Martindale JL, Klotz LO, Aw TY, Holbrook NJ. Gadd153 sensitizes cells to endoplasmic reticulum stress by downregulating $\mathrm{Bcl} 2$ and perturbing the cellular redox state. Mol Cell Biol 2001; 21(4): 1249-59.

[43] Oyadomari S, Mori M. Roles of CHOP/GADD153 in endoplasmic reticulum stress. Cell Death Differ 2004; 11(4): 381-9.

[44] Bakhshi J, Weinstein L, Poksay KS, et al. Coupling endoplasmic reticulum stress to the cell death program in mouse melanoma cells: effect of curcumin. Apoptosis 2008; 13(7): 904-14.

[45] Sato N, Urano F, Yoon Leem J, et al. Upregulation of BiP and CHOP by the unfolded-protein response is independent of presenilin expression. Nat Cell Biol 2000; 2(12): 863-70.

[46] Tajiri S, Yano S, Morioka M, et al. CHOP is involved in neuronal apoptosis induced by neurotrophic factor deprivation. FEBS Lett 2006; 580(14): 3462-8.

[47] Wang XZ, Lawson B, Brewer JW, et al. Signals from the stressed endoplasmic reticulum induce $\mathrm{C} / \mathrm{EBP}-$ homologous protein (CHOP/GADD153). Mol Cell Biol 1996; 16(8): 4273-80.

[48] Mcleod J, Kovacs L, Gaskill M, et al. Familial neurohypophyseal diabetes insipidus associated wtih a signal peptide mutation. J Clin Endocrinol Metab 1993; 77: 599A-G.

[49] Bahnsen U, Oosting P, Swaab DF, et al. A missense mutation in the vasopressin-neurophysin precursor gene cosegregates with human autosomal dominant neurohypophyseal diabetes insipidus. EMBO J 1992; 11: 19-23.

[50] Mahoney CP, Weinberger E, Bryant C, Ito M, Jameson JL. Effects of aging on vasopressin production in a kindred with autosomal 
dominant neurohypophyseal diabetes insipidus due to the DeltaE47 neurophysin mutation. J Clin Endocrinol Metab 2002; 87(2): 870-6.

[51] Repaske DR, Phillips III JA, Kirby LT, et al. Molecular analysis of autosomal dominant neurohypophyseal diabetes insipidus. J Clin Endocrinol Metab 1990; 70: 752-7.

[52] Christensen JH, Siggaard C, Corydon TJ, et al. Differential cellular handling of defective arginine vasopressin (AVP) prohormones in cells expressing mutations of the AVP gene associated with autosomal dominant and recessive familial neurohypophyseal diabetes insipidus. J Clin Endocrinol Metab 2004; 89(9): 4521-31.

[53] Christensen JH, Siggaard C, Corydon TJ, et al. Impaired trafficking of mutated AVP prohormone in cells expressing rare disease genes causing autosomal dominant familial neurohypophyseal diabetes insipidus. Clin Endocrinol (Oxf) 2004; 60(1): 125-36.

[54] Christensen JH, Siggaard C, Corydon TJ, et al. Six novel mutations in the arginine vasopressin gene in 15 kindreds with autosomal dominant familial neurohypophyseal diabetes insipidus give further insight into the pathogenesis. Eur J Hum Genet 2004; 12(1): 44-51.

[55] Chen L, Rose JP, Breslow E, et al. Crystal structure of a bovine neurophysin II dipeptide complex at $2.8 \AA$ determined from the single-wavelength anomalous scattering signal of an incroporated iodine atom. Proc Natl Acad Sci USA 1991; 88: 4240-4.

[56] Olias G, Richter D, Schmale H. Heterologous expression of human vasopressin-neurophysin precursors in a pituitary cell line: defective transport of a mutant protein from patients with familial diabetes insipidus. DNA Cell Biol 1996; 15: 929-35.

[57] Yuasa H, Ito M, Nagasaki H, et al. Glu-47, which forms a salt bridge between neurophysin II and arginine vasopressin, is deleted in patients with familial central diabetes insipidus. $\mathrm{J}$ Clin Endocrinol Metab 1993; 77: 600-4.

[58] Zhang BJ, Yamashita M, Fields R, Kusano K, Gainer H. EGFPtagged vasopressin precursor protein sorting into large dense core vesicles and secretion from PC12 cells. Cell Mol Neurobiol 2005; 25(3-4): 581-605.
[59] Birk J, Friberg MA, Prescianotto-Baschong C, Spiess M, Rutishauser J. Dominant pro-vasopressin mutants that cause diabetes insipidus form disulfide-linked fibrillar aggregates in the endoplasmic reticulum. J Cell Sci 2009; 122: 3994-4002.

[60] Kim PS, Hossain SA, Park YN, et al. A single amino acid change in the acetylcholinesterase-like domain of thyroglobulin causes congenital goiter with hypothyroidism in the $\operatorname{cog} / \operatorname{cog}$ mouse: a model of human endoplasmic reticulum storage diseases. Proc Natl Acad Sci USA 1998; 95(17): 9909-13.

[61] Muresan Z, Arvan P. Enhanced binding to the molecular chaperone BiP slows thyroglobulin export from the endoplasmic reticulum. Molecular endocrinology (Baltimore Md) 1998; 12(3): 458-67.

[62] Kim PS, Bole D, Arvan P. Transient aggregation of nascent thyroglobulin in the endoplasmic reticulum: relationship to the molecular chaperone, BiP. J Cell Biol 1992; 118(3): 541-9.

[63] Wan S, Shi P, Zhang X, Gu C, Fan S. Stronger expression of CHOP and caspase 12 in diabetic spinal cord injury rats. Neurol Res 2009; 31(10): 1049-55.

[64] Ma Y, Brewer JW, Diehl JA, Hendershot LM. Two distinct stress signaling pathways converge upon the CHOP promoter during the mammalian unfolded protein response. J Mol Biol 2002; 318(5): 1351-65.

[65] Gregersen N, Bross P, Vang S, Christensen JH. Protein misfolding and human disease. Annu Rev Genomics Hum Genet. [Research Support, Non-U.S. Gov't Review 2006; 7: 103-24.

[66] Bergeron C, Kovacs K, Ezrin C, Mizzen C. Hereditary diabetes insipidus: an immunohistochemical study of the hypothalamus and pituitary gland. Acta Neuropathol Case Rep 1991; 81(3): 345-8.

[67] Fluck CE, Deladoey J, Nayak S, et al. Autosomal dominant neurohypophyseal diabetes insipidus in a Swiss family, caused by a novel mutation (C59Delta/A60W) in the neurophysin moiety of prepro-vasopressin-neurophysin II (AVP-NP II). Eur J Endocrinol Case Reports Research Support, Non-U.S. Gov't. 2001; 145(4): 439-44.

Received: June 20, 2011

Revised: August 30, 2011

Accepted: September 05, 2011

(C) Yan et al.; Licensee Bentham Open.

This is an open access article licensed under the terms of the Creative Commons Attribution Non-Commercial License (http://creativecommons.org/licenses/by-nc/3.0/) which permits unrestricted, non-commercial use, distribution and reproduction in any medium, provided the work is properly cited. 